\title{
A RENOVAÇÃO DO ESPAÇO CITADINO E O MARKETING URBANO Três projetos urbanos sob a mesma lógica do consenso de massa em Maringá (PR)
}

\author{
THE RENEWAL OF THE CITIZEN SPACE AND URBAN \\ MARKETING \\ Three urban projects under the same logic of mass consensus in \\ Maringá (PR)
}

\author{
A. Maysa Pinhata Battistam \& B. Beatriz Fleury e Silva \\ DAU, Centro de Tecnologia; Universidade Estadual de Maringá, Brasil \\ maysabattistam@gmail.com \\ bfsilva@uem.br
}

\begin{abstract}
RESUMO
Este artigo tem como objetivo discutir as semelhanças e diferenças da estratégia de marketing urbano na renovação da cidade, lógica estabelecida por meio do empreendedorismo urbano. Para traçar um comparativo entre as aproximações e os distanciamentos, são estudados três projetos de renovação urbana propostos para espaços públicos na cidade de Maringá. Por meio do estudo de caso, percebeu-se que a ação mais intensa do marketing urbano possibilita a criação de consenso de massa, alinhando-se, assim, com os projetos de renovação, como no caso dos projetos Ágora e Eurogarden, pensados para Maringá. Quando o marketing urbano não se faz tão presente e estratégico, a população se posiciona de forma mais crítica em relação às intervenções urbanas, como se deu no projeto do centro cultural no local onde existia a rodoviária de Maringá. Revela-se assim, o marketing urbano como elemento estruturador das renovações citadinas.
\end{abstract}

Palavras-chave: marketing urbano, projeto, renovação urbana, Maringá.

Linha de Investigação: 1. Cidade e projeto. Tópico: Planejamento, políticas e governança.

\section{ABSTRACT}

This article aims to discuss the similarities and the differences of city marketing strategy in urban renewal, an established approach by urban entrepreneurialism. In order to make comparisons between the approaches and the gaps, we study tree urban renewal projects, which were proposed to publics spaces of Maringá city. Through the case study, we observed that the more intense the action of city marketing is, it enables the creation of mass consensus, so the people seem more prone to agree with the renewal projects, like in the Ágora and Eurogarden projects. When the city marketing is not current and strategic, the population use to take a more critical posture about the urban interventions, such as taken with the cultural center project. To conclude, it was highlighted that the city marketing is a structuring elementat in the urban renewal. 



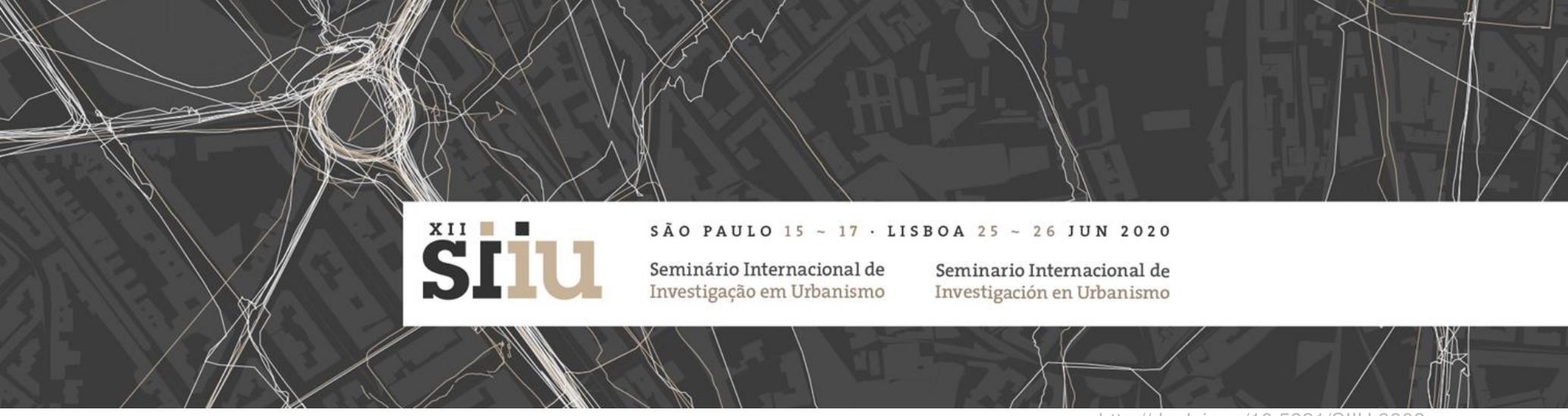

dentro de um raio de cerca de $150 \mathrm{~km}$. Dessa forma, o objeto de estudo desta pesquisa são três projetos de renovação urbana propostos para a cidade, a partir dos quais se questiona: [1] A lógica utilizada pelo marketing urbano é a mesma em todos os três projetos de renovação na cidade de Maringá? [2] Como o marketing urbano consegue estabelecer consensos de massa sobre essas intervenções urbanas?

Dessa forma, este artigo tem como principal objetivo compreender como se dá a lógica do marketing urbano para a promoção de projetos de renovação da cidade de Maringá, tendo como pressuposto de que o marketing estabelece um consenso entre a massa popular para legitimar projetos de renovação urbana.

O método utilizado nesta pesquisa foi o estudo de caso, com a tática do estudo histórico, fazendo uma a análise empírica dos casos maringaenses. Foram elencados três projetos de renovação propostos para Maringá que possuem o espaço público como característica em comum: o projeto para o local do complexo ferroviário (Ágora/Novo Centro), o projeto para a estação rodoviária (Estacionamento/Terminal Intermodal) e o projeto para o aeroporto desativado Gastão Vidigal (Eurogarden), conforme mostra a Figura 01 com a localização dos projetos na malha urbana maringaense.

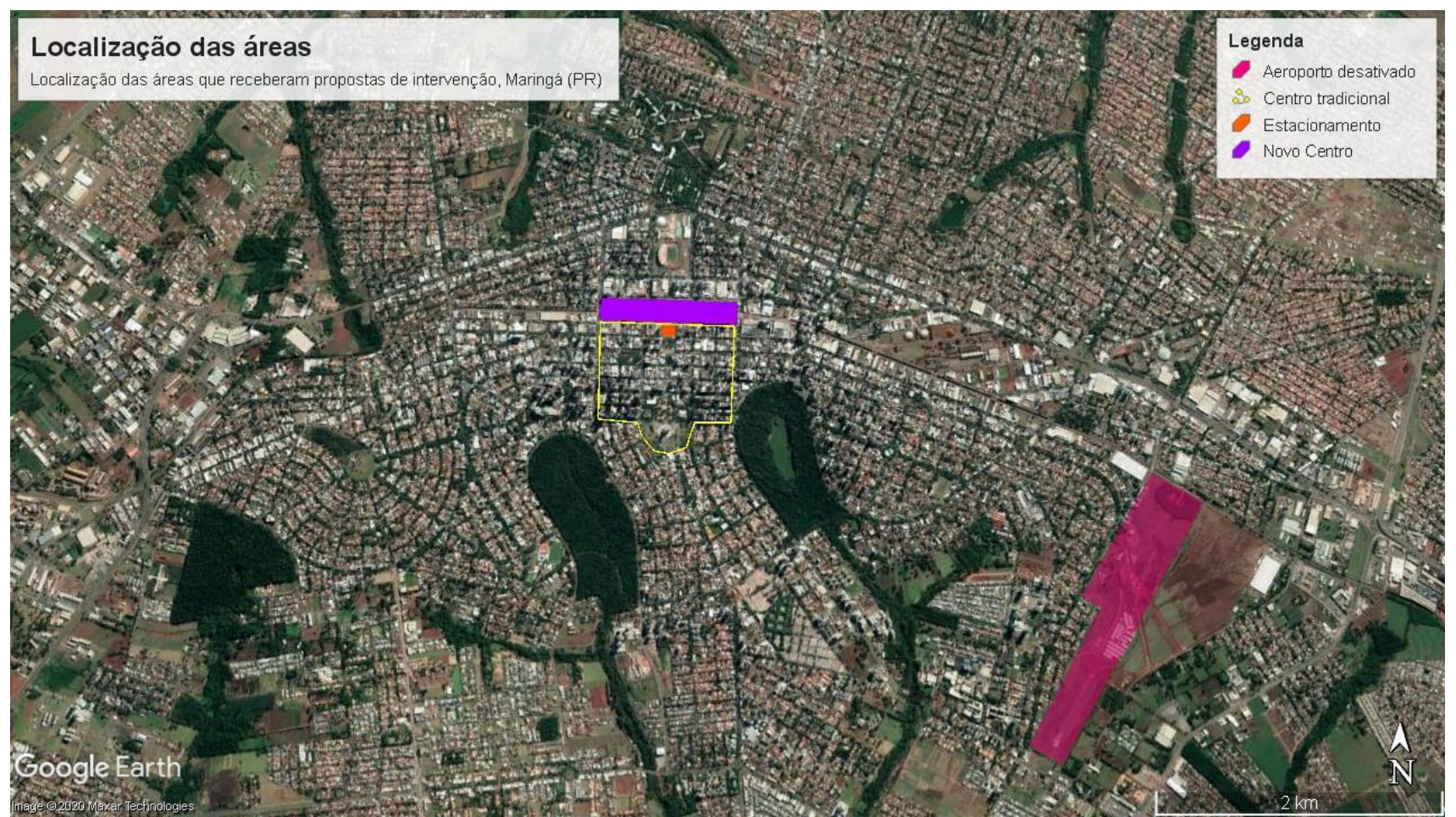

Fig. 01. Localização das áreas que receberam propostas de intervenções. O quadrado laranja era o local da rodoviária, o retângulo roxo era o local do complexo ferroviário e a mancha maior rosa é o aeroporto desativado. Fonte: GOOGLE EARTH PRO, 2020, modificada pela autora, 2020

As principais fontes de dados foram os veículos de comunicação que foram de maior relevância para Maringá: as revistas Tradição (1981-1995) e Pois é (1986-1991) e o jornal O Diário do Norte do Paraná (2008-2018), além da Prefeitura Municipal de Maringá. Os dados coletados foram notícias, reportagens e legislações sobre os três projetos nas três diferentes fontes. A partir da coleta de dados, analisou-se a forma 


\section{XII

como a renovação da cidade foi anunciada para a grande massa populacional, assim como uma comparação das características dos projetos urbanos propostos e da realidade da cidade construída. Aspectos como se o discurso e a imagem se transformaram em realidade citadina foram considerados, assim como a reação pública da sociedade vinculada a cada um dos projetos, buscando verificar se o consenso de massa foi estabelecido ou se houve algum movimento crítico em relação à intervenção. Todos os três projetos urbanos são em áreas públicas e envolveram a desativação de um meio de transporte, além disso, também possuem em comum o alinhamento com um dos slogans de Maringá: "a cidade planejada", conforme se discorre em seguida.

O artigo foi divido em dois itens. O primeiro tem como objetivo descrever e elencar os fatos históricos importantes sob a perspectiva da crítica do marketing urbano nos três projetos de modo individual; em um segundo momento, articula-se, portanto, esses resultados em uma discussão que alinha os aspectos em comum com a fundamentação teórica.

\section{Destruir para reconstruir: projetos de renovação urbana para acúmulo do capital}

\subsection{O "trator do progresso" passa pelo Complexo Ferroviário de Maringá: propõem-se Projeto Ágora, torna-se Novo Centro}

O projeto Ágora nasce como uma solução para os problemas que surgiram na cidade de Maringá após sua expansão. A cidade foi planejada por Jorge Macedo Vieira, em 1947, e possui ressonâncias do movimento de cidade-jardim (Cordovil, 2010). Como resultado dessas ressonâncias, Maringá possuía a estação ferroviária e o pátio de manobras no centro da cidade. Em meados da década de 1980, a popularização do rodoviarismo, o aumento do fluxo Norte e Sul na cidade e a decadência da ferrovia contribuíram para que o pátio de manobras e a estação ferroviária passassem a ser colocados como empecilhos na malha urbana (Grzegorczyk, 2000).

Nota-se que a mídia contribuía com a idealização de que manter a região do complexo ferroviário no centro da cidade era algo negativo. Concomitantemente, era construída paulatinamente a opinião da renovação do mesmo local, sendo divulgada como algo positivo, independente de uma análise crítica sobre a intervenção. A revista Tradição de outubro de 1987, por exemplo, traz a seguinte manchete: "De fato está acontecendo: os prédios antigos construídos na época do pioneirismo, vão sendo derrubados e substituídos por edificações modernas e sofisticadas, conforme o progresso exige [...] sob o impacto do trator do progresso" (Tradição, 1987, p.03, grifo nosso).

A partir dessas colocações de degradação do complexo ferroviário, propuseram a demolição da estação ferroviária e a criação de um novo centro, que na realidade seria um centro expandido, dado que o centro tradicional seria muito próximo a essa região. Dessa forma, o poder público lidera esse projeto e cria, em 1985, a empresa de economia mista URBAMAR, a qual teve a responsabilidade de executar o projeto urbano (LC 1934/1985). Para a elaboração do mesmo foi anunciada, antes mesmo de existir um contrato assinado com a URBAMAR, a contratação de Oscar Niemeyer, arquiteto brasileiro reconhecido internacionalmente (Grzegorczyk, 2000). 



\section{SÃOPAULO15 $\quad 17 \cdot$ LISBOA $25 \sim 26$ JUN 2020

modificação da atual Avenida João Paulino, recuando a avenida para a criação de lotes para comercializar (Ferreira, 2017). Parte das glebas do complexo ferroviário foram utilizadas para a construção de uma avenida, pois onde já existia a via, foi transformada em lotes para mercantilizar.

Apesar do atendimento ao pedido dos empresários no que tange a licitação e o projeto, o Plano Diretor foi engavetado. Em 1993, o projeto Ágora se transforma em Novo Centro por meio da LC 23/1993, termo bastante utilizado pelos meios de comunicação e popularmente adotado. $O$ projeto se transformou em um loteamento comum, com uns dos coeficientes de aproveitamento mais altos da cidade. Sendo assim, reduziu-se drasticamente a quantidade de espaço público que existia na região e criou-se uma das áreas mais adensadas de Maringá, um aglomerado de edifícios, como mostra a Figura 03.

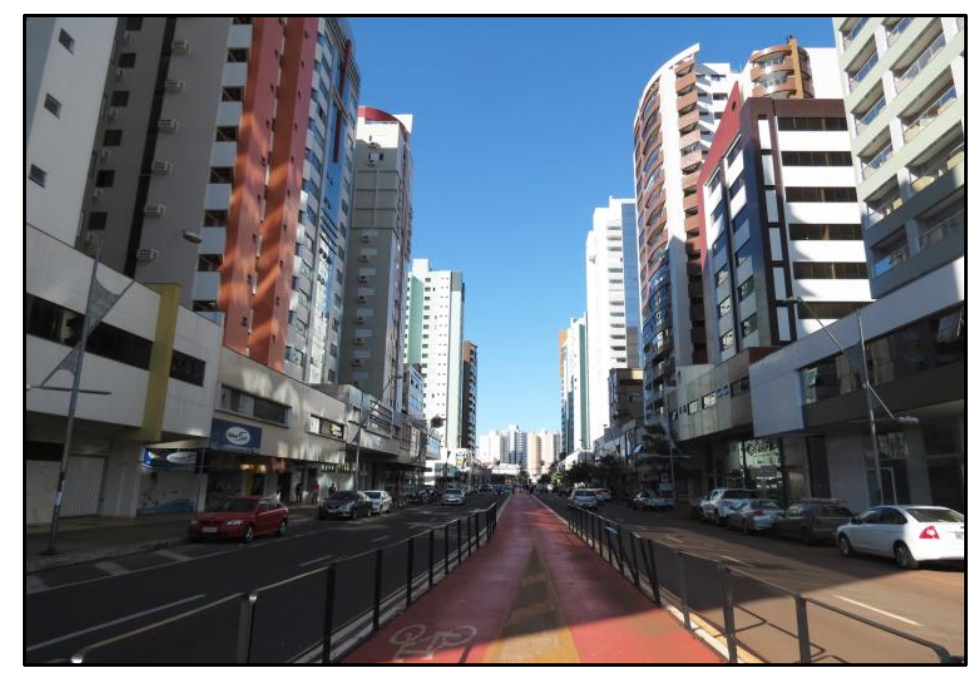

Fig. 03. Novo centro atualmente. Fonte: arquivo pessoal, 2019.

\subsection{A demolição como renovação: transformação da Estação Rodoviária Américo Dias Ferraz em estacionamento}

A estação rodoviária, inaugurada em 1962, foi construída em parte da extensão que seria da Praça Napoleão Moreira da Silva, na gestão do segundo prefeito de Maringá e idealizador do projeto, Américo Dias Ferraz, homenageado pelo prefeito Said Ferreira anos depois dando seu nome a estação (Souza, 2017). A estação rodoviária estava alinhada ao complexo ferroviário da cidade e, consequentemente, ao centro cívico de Maringá, corroborando as ressonâncias do conceito de cidade jardim (Cordovil, 2010).

De acordo com Souza (2017), o responsável pela construção da terceira rodoviária de Maringá (Figura 04), foi a empresa privada Gelson E. Gubert. Conforme Cordovil (2010), a escolha dessa localização para a construção da rodoviária contrariou as decisões da CMNP, que mesmo depois da implantação da cidade de Maringá em 1947, influenciou nas decisões da gestão pública do município. 


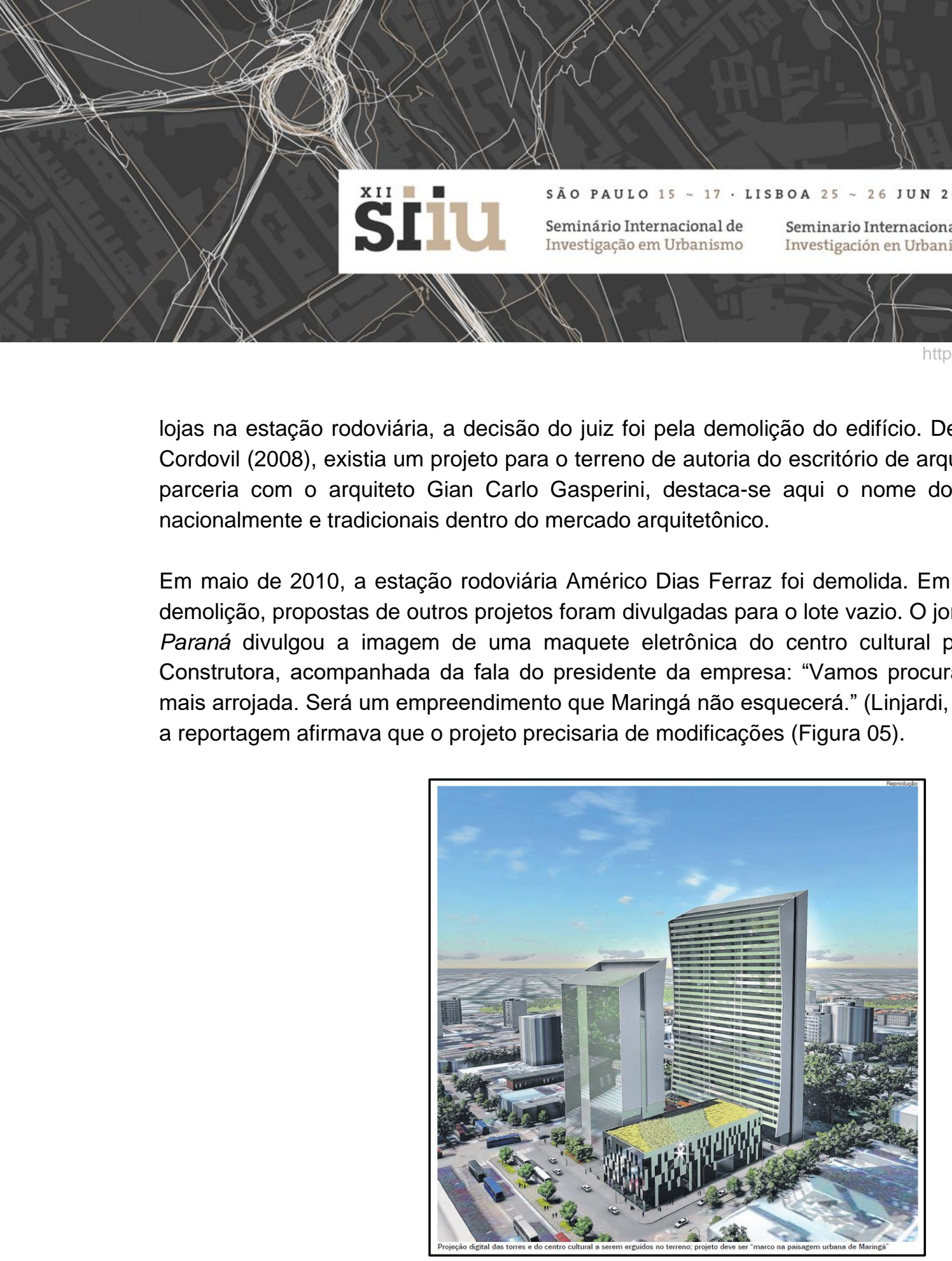

Fig. 05. Primeiro projeto proposto para o terreno da estação rodoviária demolida. Fonte: O DIÁRIO DO NORTE DO PARANÁ, 2012.

Em abril de 2013, a Prefeitura Municipal de Maringá divulga a notícia com imagens de outro projeto, afirmando que será construído, com a proposta de duas torres de 36 andares com área total de 77,6 mil e financiado por meio de uma parceria pública-privada, conforme a Figura 06. Segundo o prefeito da gestão na época, o projeto atrairia investidores para essa região. Mesmo o lote sendo o espaço público, a proposta era construir em parte dele, um residencial vertical, um centro empresarial, um hotel e restaurantes. Apesar da divulgação do projeto, até o momento, nenhum edifício foi construído no local e o lote se tornou, provisoriamente, um grande estacionamento. 


\section{SÃOPAULO15 $17 \cdot$ LISBOA $25 \sim 26$ JUN 2020 \\ Seminário Internacional de Investigação em Urbanismo \\ Seminario Internacional de Investigación en Urbanismo}

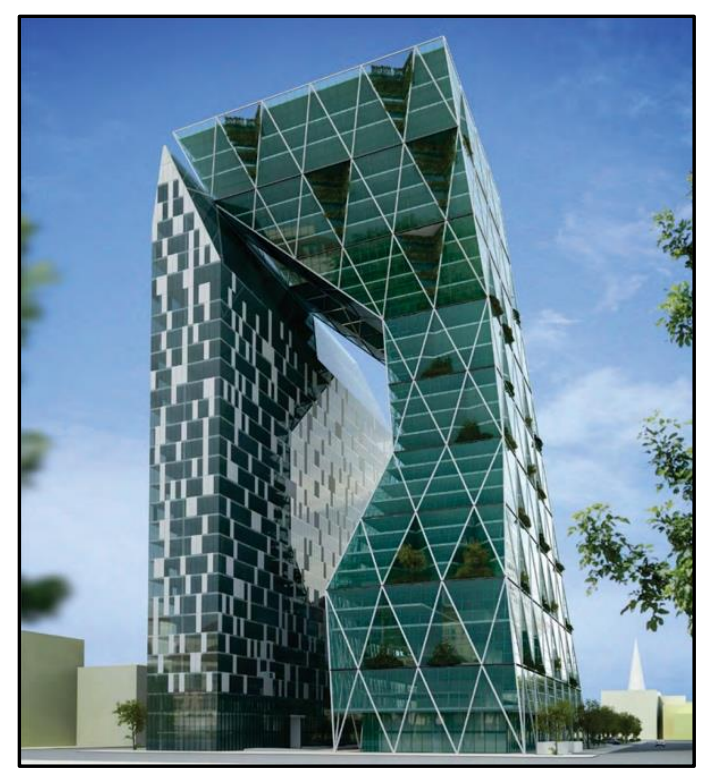

Fig. 06. Segundo projeto proposto para o terreno da estação rodoviária demolida. Fonte: Prefeitura Municipal de Maringá, 2013. Disponível em: <http://www2.maringa.pr.gov.br/site/index.php?sessao=6b5df5c63a556b\&id=19364>. Acessado em: 20 de fevereiro de 2020.

Entretanto, em frente ao lote da demolida estação rodoviária e onde existia parte do complexo ferroviário que se manteve como espaço público (área explorada no item anterior), foi construído o Terminal Intermodal de Maringá, um projeto que contrasta com a paisagem do entorno. Há especulações de que o formato adotado do edifício com arcos amarelos tem a intenção de remeter a estação rodoviária Américo Dias Ferraz, que cumpria a mesma função (Figura 07). Coincidentemente, o nome do Terminal Intermodal é Said Felício Ferreira, autor da homenagem a Américo Ferraz.

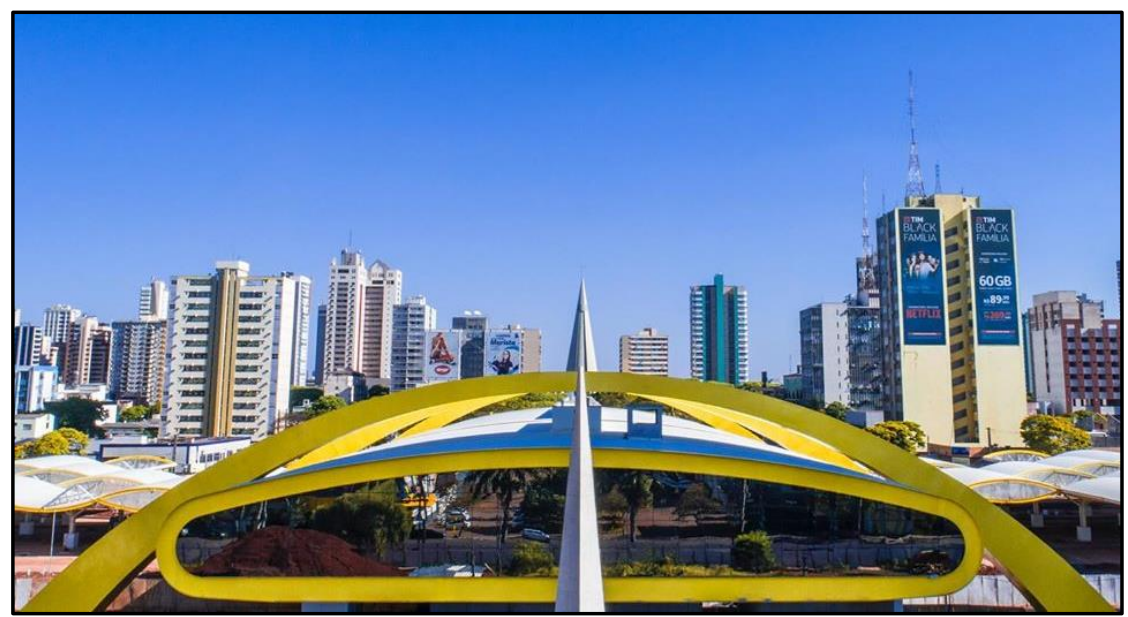

Fig. 07. Terminal Intermodal de Maringá. Fonte: Thiago Louzada, 2019. 



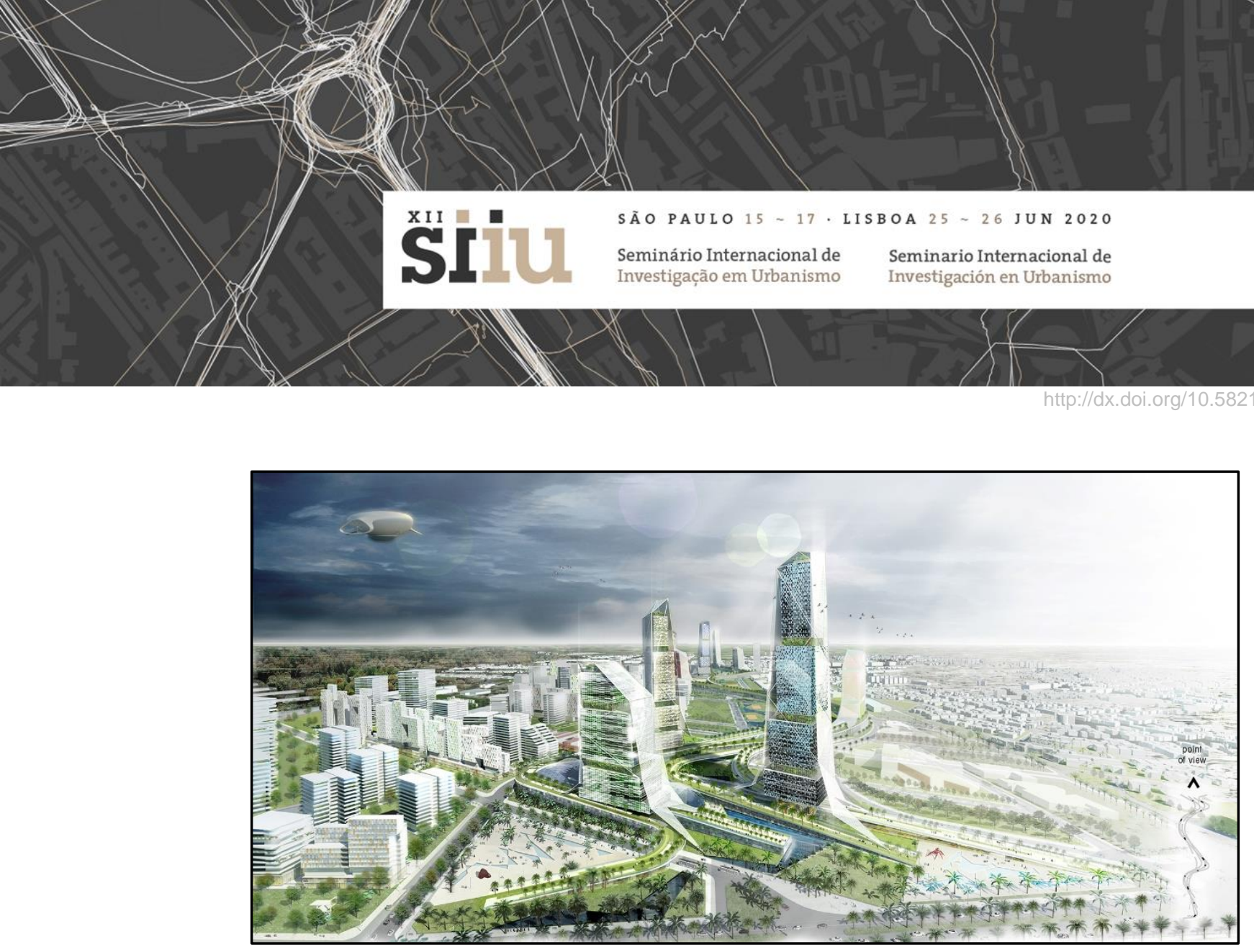

Fig. 08. Perspectiva do projeto Eurogarden. Fonte: ARCHI5, 2011. Disponível em: <https://archi5.fr/portfolio/urbanisme-maringa/>. Acessado em: 20 de fevereiro de 2020.

Destaca-se também que os edifícios que existem no local, como o terminal de passageiros construído na década de 1970, não aparece como sendo um potencial edifício de interesse histórico no projeto Eurogarden. Somente a pista de pouso do aeroporto é considerada e representada em algumas imagens do projeto. Os outros edifícios que abrigam os órgãos judiciários também não são citados nas descrições ou representados na imagem, demonstrando assim a negligência do projeto em relação ao contexto real do local.

As ações de promoção de imagens do Eurogarden foram amplas, alcançando revistas internacionais, como a Forbes (2014), nacionais como a revista Exame (2013), regionais como a Obra Prima (VICENTE, 2012) e, nitidamente, a imprensa local. Nota-se, portanto, que o marketing atrelado ao projeto Eurogarden teve repercussão em diferentes escalas, consequentemente, atingindo mais pessoas que os outros dois projetos, com divulgações concentradas nos veículos de comunicação locais.

Antes mesmo da divulgação pública do projeto, alterações nas leis urbanísticas básicas já tinham sido realizadas e essas eram direcionadas à região em que seria implantado o Eurogarden. Em 2013, o poder público adota oficialmente o projeto Eurogarden, mesmo o tendo apoiado publicamente desde 2011. Cria-se a LC 946 Operação Urbana Consorciada Novo Centro Cívico-Eurogarden, proposta pelo Executivo e aprovada pela Câmara dos Vereadores em 2013.

Cinco anos após a aprovação da legislação, a mesma é revogada por meio de um requerimento feito pelo próprio proprietário do empreendimento Eurogarden. Embora a União tivesse, dentro desses cinco anos, concedido para o munícipio a posse das vias públicas para serem construídas de acordo com o projeto Eurogarden (Gatti, 2015). 


\section{SÃOPAULO15 17 LISBOA $25 \sim 26$ JUN 2020

\section{O marketing urbano como condicionador e legitimador das transformações maringaenses}

O marketing urbano é um dos instrumentos utilizados pelo empreendedorismo urbano, tendo como principais funções estabelecer consensos de massa sobre a intervenção na cidade e atrair investidores e consumidores para esses novos empreendimentos (Compans, 2005; Sánchez, 2010). Dessa forma, embora o processo das três renovações urbanas descritas no item 1 não terem sido simultâneas, mas sequenciais, percebe-se alguns traços semelhantes entre elas.

Uma das características que mais se destaca e que compõe a estratégia de marketing urbano é a das imagens dos projetos. Mesmo o projeto Ágora, representado por maquete, pode-se observar algumas semelhanças em relação aos edifícios propostos nos três projetos. Apesar das funções e autoria serem diferentes entre eles, percebe-se que há certa padronização em executar edifícios com diversos pavimentos, estabelecendo um alto gabarito em relação ao entorno próximo e com grandes fachadas de vidros. Dessa forma, o que é vendido como sendo a modernidade e o progresso, por vezes, não é tão novo assim.

O formato de edifício em si é variável, nota-se também que, com o avanço tecnológico, se ampliou a possibilidade de criar edifícios mais anamorfos. De acordo com Arantes (2012), a tecnologia permitiu a criação de obras monumentais e surrealistas, que cumprem a função espetacular do edifício, contribuindo ainda mais para a estratégia de marketing urbano.

Nota-se que a espetacularização da arquitetura foi um recurso utilizado por todos os projetos, principalmente pelo caráter monumental das propostas. De uma forma mais enfática, o projeto Ágora e o projeto Eurogarden intensificaram o espetáculo por meio da arquitetura de marca (Valença, 2016), contratando arquitetos com nomes internacionais para elaborarem o projeto, conquistando assim, uma credibilidade maior e um "diferencial" para atrair olhares para essas intervenções. Esse recurso da espetacularização é uma forma de efetivar o consenso de massa, pois segue a mesma lógica do "pão e circo", é uma distração para que a população se mantenha alienada da produção da cidade.

Outro aspecto importante é que para que as renovações acontecessem, o espaço existente foi sendo degradado no imaginário popular, pelos discursos dos agentes e, por vezes, pelos próprios meios de comunicação, criando uma ideia negativa do local. De acordo com Schumpeter (1984) o capitalismo se utilizada da destruição criativa: é preciso destruir aquilo que foi criado para então recriá-lo e, com isso, lucrar. Na produção do espaço urbano, o mesmo ocorre. É necessário recriar localizações para que o capital gire.

Além de todas as intervenções terem sido propostas em áreas envoltas pela malha urbana consolidada e, algumas nem estarem obsoletas, todas eram áreas públicas. Compreende-se que o poder público dá suporte para essas iniciativas privadas e que as parcerias público-privadas geralmente estão pautadas somente no interesse privado. Em duas propostas estava nítido que o empreendimento imobiliário residencial e, no caso do projeto Ágora, condomínios residenciais verticais foram o resultado real do projeto proposto. 


\section{SÃOPAULO15 $\sim 17$ LISBOA $25 \sim 26$ JUN 2020

Por fim, percebe-se que em todos os três projetos o marketing urbano foi um elemento fundamental e, especificamente no projeto Ágora e no projeto Eurogarden, ele esteve atuante de modo incisivo, pois os projetos foram passivamente aceitos pela população. De modo diferente do que ocorreu no projeto do centro cultural para o lote da rodoviária, o marketing urbano nesta situação não parece ser tão intenso, apesar de encontrarmos elementos de sua presença, como a arquitetura de marca e sua espetacularização (Valença, 2016). Neste último caso, existiu um movimento da população para a preservação do edifício, ocupado por comércio popular, abrindo precedentes para compreender que não houve uma total alienação da população em relação a essa intervenção.

\section{Conclusão}

Considerando a análise e a discussão dos três projetos apresentados, conclui-se que as lógicas para estabelecer os consensos de massa em Maringá foram semelhantes: as estratégias do marketing urbano. Entretanto, o modo como a narrativa do marketing foi construída, pôde modificar a eficiência dessas estratégias. Conclui-se que ao utilizar de maneira intensa a ação midiática e a arquitetura de marca, a construção da narrativa a favor do projeto foi mais eficiente, comparando o projeto Ágora e o projeto Eurogarden com o projeto do Centro Cultural.

O projeto do Centro Cultural não teve uma intensa repercussão na mídia comparado aos outros dois, o projeto se apresentou em diferentes versões, sendo que a última delas não tinha assinatura de um personagem reconhecido no meio arquitetônico e foi apresentado após a demolição do edifício da estação, mas foi o único projeto que a massa popular se manifestou contra a intervenção. Se diferenciando dessa forma, tanto do projeto Ágora quanto do projeto Eurogarden, que até receberam nomes emblemáticos para compor a narrativa marqueteira, estavam presentes em outros elementos que serviram como plataforma de marketing, como o evento URBE 6 e o plano Maringá 2030, proporcionando assim maior credibilidade aos projetos. Ambos foram intervenções aceitas, e mais do que isso, conseguiram alterar legislações urbanísticas básicas para a execução dos projetos.

Apesar de os projetos buscarem a representação de uma modernidade, nenhum deles foi construído conforme a imagem, evidenciando que as imagens compunham somente uma campanha de marketing baseada no espetáculo, pois há dúvidas como, em relação ao projeto Eurogarden, se existe tecnologia no interior do Paraná para construir tal monumentalidade. Conclui-se que a renovação do espaço citadino nem sempre entrega o resultado esperado, e tem como elemento principal o marketing urbano, construído por meio de imagens de uma arquitetura espetacular e narrativas midiáticas.

\section{Referências bibliográficas}

ARANTES, P. (2012). Arquitetura na era digital - financeira: desenho, canteiro e renda da forma. 1ª Ed, São Paulo: Editora 34.

COMPANS, R. (2005). Empreendedorismo urbano: entre o discurso e a prática. 1ª Ed. São Paulo: Editora Unesp. 


\section{SÃO PAULO15 17 LISBOA $25 \sim 26$ JUN 2020

CORDOVIL, F. C. S. (2010). A aventura planejada: engenharia e urbanismo na construção de Maringá, PR 1947-1982. 2010. (Tese) EESC, USP.

FERREIRA, J. (2017) O processo de privatização do espaço No novo centro de MaringáParaná: agentes, imagens e discursos. 2017. (Dissertação) UEM.

GATTI, M. (2015). União faz doação do sistema viário do Novo Centro Cívico, O Diário do Norte do Paraná, Maringá, ano XL, no 12.678, Zoom, p. A3.

GRZEGORCZYK, V. (2000) Novo Centro de Maringá: estratégias e conflitos na produção do espaço urbano. (Dissertação) Universidade Estadual Paulista. Faculdade de Ciências e Tecnologia. Campus de Presidente Prudente. Mestrado em Geografia.

HARVEY, D. (2006). A produção capitalista do espaço. 2 ed. São Paulo: Annablume.

LINJARDI, F. (2012). Projeto para terreno da antiga rodoviária vai mudar. O Diário do Norte do Paraná. Maringá, ano XXXIX, no 11.903, ZOOM, p. A3.

Lei Ordinária ํo 1934 (1985). Cria uma sociedade de economia mista, sob a denominação de Urbanização de Maringá S/A, destinada especificamente a viabilizar com a rede ferroviária federal S/A - RFFSA, a remoção e transferência do complexo ferroviária. Maringá, 10 de outubro de 1985.

Lei Ordinária no 3051 (1991). Aprova o Plano Diretor denominado "Projeto Ágora de Maringá". Maringá, 24 de dezembro de 1991.

Lei Complementar no 23 (1993). Aprova o Plano Diretor da área denominada Novo Centro de Maringá. Maringá, 29 de out. de 1993.

MUNHOZ, V. (2010). Projeto de centro cultural é mantido. O Diário do Norte do Paraná. Maringá, ano XXXVI, no 11.094, Cidades, p. A5.

O DIÁRIO DO NORTE DO PARANÁ. (2008). Enquete do dia: Você é favorável a construção de um prédio de até 36 andares no lugar da rodoviária velha? O Diário do Norte do Paraná. Maringá, ano XXXIV, no 10.537, p. A2.

REVISTA TRADIÇÃO. (1987). Agora sai a grande “Ágora” de Maringá. Tradição, no66, p. 16-17.

SÁNCHEZ, F. (2003) Os sentidos da cidade - espetáculo. In: SÁNCHEZ, Fernanda. A reinvenção das cidades para um mercado mundial. Chapecó: Argos.

SCHUMPETER, J. (1984). Capitalismo, socialismo e democracia. Rio de janeiro: Zahar Editores.

SOUZA, F. D. (2017). As três primeiras rodoviárias de Maringá (PR): o uso da fotografia para a recuperação e contextualização de dados históricos. (Dissertação) UEL.

VAINER, C. (2000). Pátria, empresa e mercadoria. Notas sobre a estratégia discursiva do Planejamento Estratégico Urbano. In: ARANTES, Otília; VAINER, Carlos; MARICATO, Ermínia. (org). A cidade do pensamento único. Desmanchando consensos. 2ª Ed. Petrópolis: Vozes, 2000. 


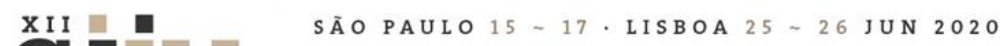

VALENÇA, M. M. (2016). Arquitetura de Grife na Cidade Contemporânea: tudo igual, mas diferente. Rio de Janeiro: MAUAD.

\section{Fontes eletrônicas}

ANDRADE, C. R. M.; CORDOVIL, F. C. de S. (2008). A cidade de Maringá, PR. O plano inicial e as "requalificações urbanas". X Coloquio Internacional de Geocrítica, Universidad de Barcelona, 26-30 de mayo de 2008. Disponível em: <http://www.ub.es/geocrit/-xcol/55.htm> Acessado em: 05 de março de 2020.

BARROS, D. (2013). Boas ideias para os prefeitos. Revista Exame. Disponível em: <http://bit.ly/2WYynJg>, Acessado em 10 de junho de 2019.

FORBES (2014). Brazil: The Long Game. Forbes. Disponível em:

$<$ https://www.forbes.com/custom/2014/12/29/brazil-the-long-game/>. Acessado em: 25 de novembro de 2019.

VICENTE, A. (2012). Novo Centro Cívico de Maringá - O futuro não demora. Arquitetando na tv. Disponível em:< http://arquitetandonatv.blogspot.com/2013/03/novo-centro-civico-de-maringa-o-futuro.html> Acessado em: 25 de novembro de 2019. 